\title{
Antimicrobial susceptibility patterns of Ureaplasma species and Mycoplasma hominis in pregnant women
}

Mathys J Redelinghuys ${ }^{1 *+}$, Marthie M Ehlers ${ }^{1,2 \dagger}$, Andries W Dreyer ${ }^{1,2+}$, Hennie A Lombaard ${ }^{3}$ and Marleen M Kock ${ }^{1,2+}$

\begin{abstract}
Background: Genital mycoplasmas colonise up to $80 \%$ of sexually mature women and may invade the amniotic cavity during pregnancy and cause complications. Tetracyclines and fluoroquinolones are contraindicated in pregnancy and erythromycin is often used to treat patients. However, increasing resistance to common antimicrobial agents is widely reported. The purpose of this study was to investigate antimicrobial susceptibility patterns of genital mycoplasmas in pregnant women.
\end{abstract}

Methods: Self-collected vaginal swabs were obtained from 96 pregnant women attending an antenatal clinic in Gauteng, South Africa. Specimens were screened with the Mycofast Revolution assay for the presence of Ureaplasma species and Mycoplasma hominis. The antimicrobial susceptibility to levofloxacin, moxifloxacin, erythromycin, clindamycin and tetracycline were determined at various breakpoints. A multiplex polymerase chain reaction assay was used to speciate Ureaplasma positive specimens as either U. parvum or U. urealyticum.

Results: Seventy-six percent (73/96) of specimens contained Ureaplasma spp., while 39.7\% (29/73) of Ureaplasma positive specimens were also positive for $M$. hominis. Susceptibilities of Ureaplasma spp. to levofloxacin and moxifloxacin were 59\% (26/44) and 98\% (43/44) respectively. Mixed isolates (Ureaplasma species and M. hominis) were highly resistant to erythromycin and tetracycline (both $97 \%$ resistance). Resistance of Ureaplasma spp. to erythromycin was 80\% (35/44) and tetracycline resistance was detected in 73\% (32/44) of Ureaplasma spp. Speciation indicated that U. parvum was the predominant Ureaplasma spp. conferring antimicrobial resistance.

Conclusions: Treatment options for genital mycoplasma infections are becoming limited. More elaborative studies are needed to elucidate the diverse antimicrobial susceptibility patterns found in this study when compared to similar studies. To prevent complications in pregnant women, the foetus and the neonate, routine screening for the presence of genital mycoplasmas is recommended. In addition, it is recommended that antimicrobial susceptibility patterns are determined.

Keywords: Pregnant women, Ureaplasma spp., Mycoplasma hominis, Antimicrobial susceptibilities

\section{Background}

Mycoplasma hominis and Ureaplasma spp., including $U$. parvum and $U$. urealyticum, are collectively known as genital mycoplasmas and are found in the vaginal milieu of up to $80 \%$ of pregnant and non-pregnant women [1]. The pathogenesis of genital mycoplasmas is still poorly

\footnotetext{
*Correspondence: shanered72@gmail.com

${ }^{\dagger}$ Equal contributors

'Department of Medical Microbiology, University of Pretoria, Pretoria, South Africa Full list of author information is available at the end of the article
}

understood. Damage related to genital mycoplasma infections might be the result of the induced immune- and inflammatory responses rather than the direct toxic effects of mycoplasma cellular components [2]. Mycoplasma hominis is specifically associated with conditions such as endometritis [3] and preterm birth [4]. Ureaplasmas are reported to be more prevalent than other mycoplasmas in the female urogenital tract, with $U$. parvum found more often than $U$. urealyticum [5]. During pregnancy, Ureaplasma spp. can cause chorioamnionitis, spontaneous abortion, stillbirth and preterm delivery [3]. Although the 
pathogenic role of $U$. urealyticum in urogenital tract infections is widely recognised [6-8], the role of $U$. parvum in these infections is not that well established [7]. Nonetheless, $U$. parvum might be present in bacterial loads leading to adverse pregnancy outcomes [9] and produce asymptomatic infections of the upper genital tract in women as frequently as $U$. urealyticum [7]. Out of the four $U$. parvum serovars (including serovars 1, 3, 6 and 14), serovars 3 and 14 have been isolated in more cases of genital tract infections than serovars 1 and $6[10,11]$. The greater virulence reported for $U$. urealyticum in some conditions might be attributed to its superior capability of acquiring genes horizontally [12].

Genital mycoplasmas display inherent resistance to beta-lactams and glycopeptides (e.g. vancomycin) because of the absence of a cell wall [13]. Although macrolides are often the drugs of choice for treating these infections, M. hominis is intrinsically resistant to the C14 and C15 macrolides (e.g. erythromycin and azithromycin) [14]. Ureaplasma species also have natural resistance to lincosamides (e.g. clindamycin) [15]. Observed resistance to macrolides is associated with mutations in the $23 \mathrm{~S}$ rRNA gene $[16,17]$, while resistance to tetracyclines is associated with the presence of the moveable tet $(\mathrm{M})$ genetic element $[18,19]$.

The administration of antimicrobial agents to pregnant women with preterm rupture of the membranes (PROM) may extend the gestation period and decrease the risks of associated complications and neonatal infections [20]. The antimicrobial agent of choice should be considered carefully, as some agents are teratogens - i.e. the agent can cause malformation or functional damage to an embryo or foetus or may have toxic effects on the neonate [21]. Macrolides are often used empirically [22] because of tetracyclines and fluoroquinolones being contraindicated in pregnancy $[20,23]$. However, the amniotic sac is not effectively penetrated by erythromycin and ureaplasmas are not eradicated from the vagina or cervix by this agent [13]. Newer macrolides (e.g. azithromycin and clarithromycin) allow for better tolerability and the once daily dosing benefit can increase compliance [13,24]. Treatment with azithromycin is equally successful compared to erythromycin but with fewer side effects $[25,26]$.

To perpetuate the effective use of antimicrobial agents, the antimicrobial activities of such agents need to be monitored frequently. The Mycofast Revolution assay (ELiTech Diagnostic, France) is a commercially available assay that allows for detection, identification and antimicrobial-susceptibility testing of genital mycoplasmas within 48 hours [27]. However, identification with this assay is limited to M. hominis and the Ureaplasma genus [27]. The speciation of genital mycoplasmas can be achieved by the use of sensitive and rapid molecular methods, such as polymerase chain reaction (PCR) assays [28]. Speciation of bacteria may assist in elucidating the pathogenesis of specific medical conditions [29]. The purpose of this study was to investigate the antimicrobial susceptibility patterns of genital mycoplasmas in pregnant women attending antenatal care.

\section{Methods}

This investigative study included pregnant women attending the antenatal and maternal and foetal unit (MAFU) clinics of a tertiary academic hospital in Pretoria, South Africa, from October 2012 to January 2013. Patients older than 18 years were included in the study. All women who participated gave written informed consent prior to commencement. Ethical approval was obtained from the Student Ethics Committee of the Faculty of Health Sciences, University of Pretoria (protocol number S6/2012) and preceded experimental work. Experimental work was conducted at the Department of Medical Microbiology, University of Pretoria.

Self-collected vaginal swabs (Copan Diagnostics, Inc, Italy) were obtained and tested for the presence of Ureaplasma species and M. hominis. Genital mycoplasmas were identified and enumerated and antimicrobial susceptibilities were determined with the Mycofast Revolution assay as indicated by the manufacturer. The swab was used to seed the UMMt transport medium of which $100 \mu \mathrm{l}$ were added to the $U$. urealyticum (UU) and $M$. hominis $(\mathrm{MH})$ wells of the Mycofast Revolution Screening tray. Additionally, $50 \mu \mathrm{l}$ of $\mathrm{MH}$ supplement (S.Mh) were added to the $\mathrm{MH}$ well; the wells were covered with two drops of sterile mineral oil; and the tray was incubated (Vacutec, South Africa) at $37^{\circ} \mathrm{C}$ for $24 \mathrm{~h}$. After $24 \mathrm{~h}$ of incubation, an orange or red colour change indicated the presence of Ureaplasma species and/or $M$. hominis. A yellow colour in the wells marked the absence of genital mycoplasmas. In the case of a positive screening test, the remainder of the seeded UMMt that was stored at $4^{\circ} \mathrm{C}$ to $8^{\circ} \mathrm{C}$ was used to inoculate the Complement Mycofast Revolution tray. One hundred microliters of UMMt medium were dispensed into wells 1 to 20 and $50 \mu \mathrm{l}$ of S. Mh were dispersed into wells 6 and 7. All the wells were covered with two drops of sterile mineral oil. The tray was incubated (Vacutec, South Africa) at $37^{\circ} \mathrm{C} \pm 1^{\circ} \mathrm{C}$ for $24 \mathrm{~h}$ (maximum $48 \mathrm{~h}$ in all cases) and the presence or absence of colour changes at defined breakpoints specified on the inoculation trays indicated resistance or susceptibility to each antimicrobial agent.

Genital mycoplasma strains were regarded as sensitive when growth was inhibited by the higher and lower critical concentrations of the antimicrobial agent. Genital mycoplasma strains were regarded as resistant when there was growth at the lower critical concentration of the antimicrobial agent but not the higher critical concentration. Strains were also regarded as resistant when there was growth at 
both the lower and higher critical concentrations of the antimicrobial agent. The specific breakpoints indicating susceptibility ( $\mathrm{S}$ ) or resistance (R) for Ureaplasma species were as follows [30]: levofloxacin $\mathrm{S} \leq 2$, $\mathrm{R} \geq 4$; moxifloxacin $\mathrm{S} \leq 2$; erythromycin $\mathrm{S} \leq 8, \mathrm{R} \geq 16$; and tetracycline $\mathrm{S} \leq 1, \mathrm{R} \geq 2$. The breakpoints for $M$. hominis are as follows: levofloxacin $S \leq 1, R \geq 2$; moxifloxacin $S \leq 0.25$; clindamycin $S \leq 0.25, R \geq 0.5$; and tetracycline $S \leq 4, R \geq 8$.

A multiplex PCR (mPCR) assay was used to determine the respective Ureaplasma species detected with the Mycofast Revolution assay. This assay was performed as described by Stellrecht et al. [3] and was validated with reference strains ATCC27813 (U. parvum) and ATCC27 619 (U. urealyticum). The multiple-banded antigen (MBA) gene of Ureaplasma served as the target gene. The amplified products were subjected to gel electrophoresis at $100 \mathrm{~V}$ for $1 \mathrm{~h}$ on a $2 \%(\mathrm{~m} / \mathrm{v})$ MetaPhor agarose gel (Lonza, USA) in 1X TBE buffer $45 \mathrm{mM}$ Tris-borate $(\mathrm{pH}$ 8.0) (Sigma Chemical co, USA), $1 \mathrm{mM}$ EDTA (Promega, Madison, USA)]. A 50 kb molecular marker (Fermentas, Thermo Scientific, USA) was used to identify band sizes, which were $403 \mathrm{bp}$ and $448 \mathrm{bp}$ in size for $U$. parvum and $U$. urealyticum, respectively [2].

The results were reported as percentages. A two-sample t-test between proportions was performed to determine whether there was a significant difference between the resistance of Ureaplasma species and mixed isolates to erythromycin and tetracycline.

\section{Results}

The study population included 96 pregnant African women. The ages of the women were normally distributed and ranged from 19 to 43 with a mean and median age of 30 . The average gestation period was 25 weeks, ranging from 10 weeks to 40 weeks. Ureaplasma species were detected in 76\% (73/96) of specimens and 39.7\% (29/73) of Ureaplasma positive specimens were also positive for M. hominis. Mycoplasma hominis was not detected alone. The colorimetric assay produced no discordant results; a slight colour change resulted in an orange colour (a positive result) and the content of none of the wells looked turbid, which was indicative of no contamination. To confirm results, all the trays were incubated for an additional 24 hours and reread. The growth of Ureaplasma species and $M$. hominis at various breakpoints of antimicrobial agents are displayed in Table 1. Ureaplasma species and $M$. hominis in a single specimen were noted as mixed isolates.

Susceptibilities of 59\% (26/44) and 98\% (43/44) in the Ureaplasma species were found for levofloxacin and moxifloxacin respectively. Eighty percent (35/44) of Ureaplasma strains were resistant to erythromycin, whereas resistance to tetracycline was detected in 73\% (32/44). Greater resistance was observed for mixed isolates against erythromycin and tetracycline [both 97\% (28/29)] at higher critical concentrations. The susceptibility patterns of the mixed isolates to levofloxacin were similar to the cases where only Ureaplasma species were detected. Mixed isolates were more resistant to moxifloxacin (Figure 1).

The mPCR assay indicated that 95\% (42/44) of the Ureaplasma positive specimens contained only $U$. parvum, while $5 \%(2 / 44)$ contained both $U$. parvum and $U$. urealyticum. None of the specimens that were positive for Ureaplasma species had only $U$. urealyticum present.

\section{Discussion}

This study, together with a previously published article [27], is the first to report antimicrobial susceptibility patterns using the Mycofast Revolution assay from genital mycoplasmas in this specific setting. The high level of antimicrobial resistance to erythromycin and tetracycline that was observed for mixed isolates could be attributed to $M$. hominis. The antimicrobial resistance was significantly higher than when only Ureaplasma species were detected ( $97 \%$ vs $80 \%$ for erythromycin, $\mathrm{p}=0.0396$; and $97 \%$ vs. $73 \%$ for tetracycline, $\mathrm{p}=0.0101$ ).

Erythromycin resistance of mixed isolates is comparable to Domingues et al. [31] and Kechagia and colleagues' [14] documentation of $90.7 \%$ and $100 \%$ erythromycin resistance respectively. Tetracycline resistance of mixed isolates was higher (97\%) when compared to similar studies (14\% to 57\%) [14,22]. Resistance of Ureaplasma species to erythromycin $(80 \%)$ is supported by some studies $(83 \%$ [14]) but not by others (17.2\% [22]). The susceptibility of Ureaplasma isolates to tetracycline was found to be $27 \%$. Other studies have reported higher tetracycline susceptibility rates for Ureaplasma isolates, ranging from $81 \%$ to $100 \%[1,14,22]$. Most of these studies reported lower tetracycline resistance rates specifically for the species $U$. urealyticum, which may explain the difference in resistance

Table 1 The distribution (\%) of Ureaplasma species and M. hominis at different breakpoints of antimicrobial agents ( $\mathbf{n}=96)$

\begin{tabular}{|c|c|c|c|c|c|c|c|c|c|c|c|c|c|}
\hline & \multicolumn{3}{|c|}{ Levofloxacin } & \multicolumn{2}{|c|}{ Moxifloxacin } & \multicolumn{2}{|c|}{ Erythromycin } & \multicolumn{2}{|c|}{ Clindamycin } & \multicolumn{4}{|c|}{ Tetracycline } \\
\hline & $1^{1}$ & 2 & 4 & 0.25 & 2 & 8 & 16 & 0.25 & 0.5 & 1 & 2 & 4 & 8 \\
\hline Sensitive (S)/Resistant (R) & $\mathrm{S}$ & $\mathbf{R}$ & $\mathbf{R}$ & $\mathrm{s}$ & $\mathbf{R}$ & $\mathbf{R}$ & $\mathbf{R}$ & $\mathbf{R}$ & $\mathbf{R}$ & $\mathbf{R}$ & $\mathbf{R}$ & $\mathbf{R}$ & $\overline{\mathbf{R}}$ \\
\hline Ureaplasma species $(n=44)$ & 52 & 30 & 11 & 93 & 2 & 70 & 9 & 0 & 100 & 25 & 16 & 2 & 30 \\
\hline Ureaplasma species and M. hominis $(\mathrm{n}=29)$ & 55 & 28 & 14 & 83 & 10 & 10 & 86 & 0 & 100 & 14 & 28 & 7 & 48 \\
\hline
\end{tabular}

${ }^{1}$ The breakpoints in $\mu \mathrm{g} / \mathrm{mL}$ according to the CLSI guidelines [30]. 


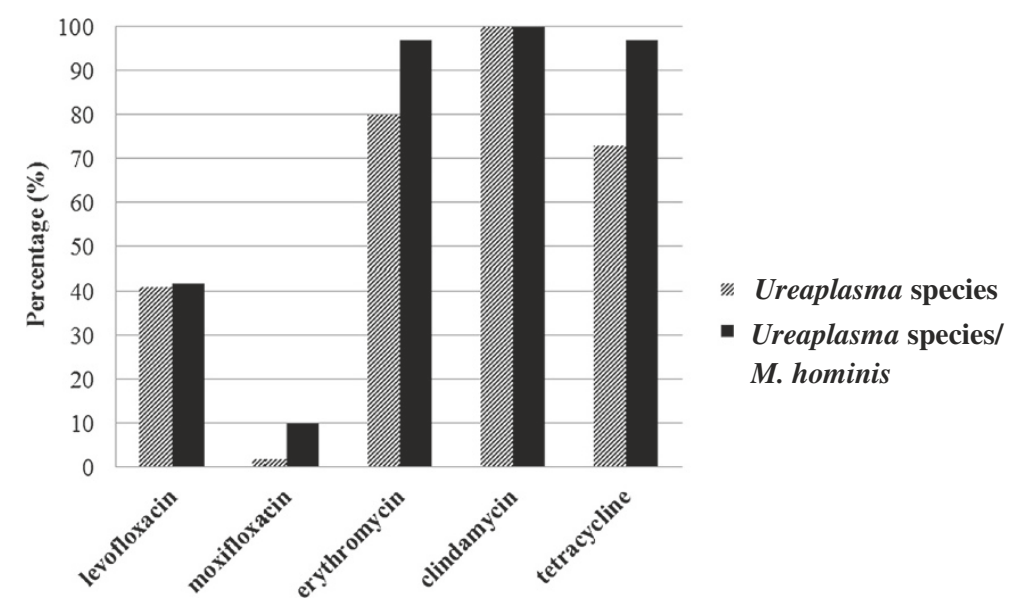

Figure 1 Antimicrobial resistance (\%) of Ureaplasma species and $M$. hominis positive specimens to various antimicrobial agents.

observed $[1,14,31]$. The demographics of the participants in the last-mentioned studies differed in the sense that one study reported on non-pregnant women of a wider age range (18-62) [14], while another reported on a group of pregnant women of gestation $>20$ weeks [1].

Results of the mPCR assay were that 95\% (42/44) of the Ureaplasma positive specimens contained only $U$. parvum, while $5 \%(2 / 44)$ contained both $U$. parvum and U. urealyticum. Ureaplasma parvum was the principal species contributing to antimicrobial resistance. Similar results were found by Povlsen et al. [32], who investigated genital mycoplasmas in pregnant women with singleton pregnancies. These studies reported that approximately 90\% of the 280 Ureaplasma positive specimens contained $U$. parvum and $3 \%$ contained both $U$. parvum and $U$. urealyticum. After speciation of the Ureaplasma positive specimens, $U$. parvum strains were discovered to confer resistance to fluoroquinolones (levofloxacin and moxifloxacin) and macrolides (erythromycin). These results are similar to those of Govender et al. [33], who reported fluoroquinolone and erythromycin resistance in $U$. parvum strains from South Africa.

Zhu and colleagues [34] reported antimicrobial susceptibilities of $10.65 \%$ and $31.27 \%$ to levofloxacin for mixed isolates and $U$. urealyticum respectively. The present study found genital mycoplasmas to be more susceptible to levofloxacin, with susceptibilities of $41 \%$ and $42 \%$ for Ureaplasma species and mixed isolates respectively.

The susceptibilities of genital mycoplasmas to antimicrobial agents differ by geographical region [22]. The difference in the antimicrobial resistance found in the present study and in reports from various countries might be the result of different antimicrobial-usage guidelines, which would lead to the resistance of bacterial strains to different antimicrobial groups [14]. Additional variables contributing to the difference in resistance may include the population studied, the study period, or the kits used for specimen processing and analyses [35]. The establishment of common guidelines for the treatment of genital mycoplasma infections is complex and effective treatment depends on the antimicrobial susceptibilities of genital mycoplasmas in a specific region $[10,14]$.

Strategies to preserve the use of current antimicrobial agents and minimise resistance to such agents may include the development of: (i) new classes of antimicrobial agents; (ii) updated derivatives of currently used antimicrobial agents and; (iii) and the use of two different antimicrobial agents for treatment instead of one agent [36]. However, effective resources are required to constantly monitor antimicrobial susceptibility profiles of such agents to ensure treatment success and good pregnancy outcomes $[10,36]$.

To circumvent the delays that may be experienced with the diagnosis of genital mycoplasma infections, the syndromic management of sexually transmitted infections (STIs) is a general treatment approach followed in South Africa. Patients are requested to report symptoms indicating the presence of an STI; e.g. vaginal discharge and/or dysuria and/or vulval itching or burning. In the present study, the symptoms that women reported were vague and subjective and did not correlate with results. The women could not definitely distinguish between a physiological discharge and an unusual vaginal discharge. Broad-spectrum antimicrobial regimens are used to cover all potential pathogens and commonly include combining a cephalosporin (e.g. cefixime) with erythromycin and metronidazole. A number of studies report that the syndromic approach is not effective in reducing the prevalence of curable STIs in asymptomatic patients [37-39]. Our study supports these findings by showing a very high percentage of resistance to erythromycin in this study group. Nonetheless, the success of the syndromic management of STIs relies on up-to-date knowledge of the infectious agents causing specific syndromes and the antimicrobial susceptibilities of these agents [40]. The frequent 
use of erythromycin in pregnant women has permitted the surveillance of long-term effects of this antimicrobial agent. These include infantile hypertrophic pyloric stenosis [41], cardiac toxicity [42] and maternal hepatotoxicity [43]. There is not yet enough data available to know whether the risks of toxicity in neonates are similar with newer macrolide antimicrobial agents [13]. If the price of azithromycin in many countries decreases to an affordable level, it may potentially replace erythromycin as a general treatment option in the future. Fluoroquinolones are classified as category $\mathrm{C}$ agents and the use of these agents in pregnancy is controversial [28]. The treatment options of genital mycoplasmas in pregnancy therefore remain limited.

Monitoring of susceptibility patterns of genital mycoplasmas may assist with optimising treatment guidelines and overall improve therapeutic outcomes. The Mycofast Revolution assay is an easy and effective way of evaluating the susceptibility of genital mycoplasmas to commonly used or potential antimicrobial agents [27].

A limitation of the study is that bacterial strains were not analysed for specific mutations where antimicrobial resistance was detected. Another limitation may be the inability of the authors to test for other pathogens, such as Neisseria gonorrhoeae and Chlamydia trachomatis and specifically for other Mycoplasma spp., such as Mycoplasma genitalium. No approved commercially available diagnostic assay exists for the detection and antimicrobialresistance testing of all genital mycoplasma species, including M. genitalium. Detection of such species is mainly by nucleic acid amplification tests (NAATs) [44]. More studies in the Pretoria region are needed to confirm the high resistance rates of genital mycoplasmas to common antimicrobial agents and to determine the specific genetic elements responsible for resistance. These studies can be performed in broader study populations, such as nonpregnant women and HIV-positive women.

\section{Conclusion}

Although the fluoroquinolones, especially moxifloxacin, remain the most effective against genital mycoplasmas, these agents are restricted to non-pregnant patients. A discrepancy in antimicrobial susceptibility in different regions emphasises the importance of routine monitoring to ensure the efficacy of treatment and curb morbidity and mortality rates.

\section{Competing interests}

The authors declare no competing of interests.

\section{Authors' contributions}

MJR was involved in concept design, laboratory work as well as writing of the manuscript. MMK, MME and AWD were involved in concept design of the study as well as critical review of the manuscript. HAL was involved in concept design of the study as well as overseeing the logistics of sample collection. All authors read and approved the final manuscript.

\section{Acknowledgements}

The authors would like to thank Separation Scientific for supplying the Mycofast Revolution kits used in this study. The authors would also like to thank the University of Pretoria, the Medical Research Council (South Africa) and the National Health Laboratory Service (NHLS) for financial assistance received. Barbara English from the research office of the University of Pretoria's faculty of health sciences is thanked for her editing of the manuscript.

\section{Author details}

${ }^{1}$ Department of Medical Microbiology, University of Pretoria, Pretoria, South Africa. 2Department of Medical Microbiology, Tshwane Academic Division, National Health Laboratory Service, Pretoria, South Africa. ${ }^{3}$ Department of Obstetrics and Gynaecology, University of Pretoria, Pretoria, South Africa.

Received: 6 December 2013 Accepted: 26 March 2014 Published: 28 March 2014

\section{References}

1. Bayraktar MR, Ozerol IH, Gucluer N, Celik O: Prevalence and antibiotic susceptibility of Mycoplasma hominis and Ureaplasma urealyticum in pregnant women. Int J Infect Dis 2010, 14:e.90-e.95.

2. Razin S, Hayflick L: Highlights of mycoplasma research - an historical perspective. Biologicals 2010, 38:183-190.

3. Stellrecht KA, Woron AM, Mishrik NG, Venezia RA: Comparison of multiplex PCR assay with culture for detection of genital mycoplasmas. J Clin Microbiol 2004, 42:1528-1533.

4. Kataoka S, Yamada T, Chou K, Nishida R, Morikawa M, Minami M, Yamada H, Sakuragi N, Minakami H: Association between preterm birth and vaginal colonization by mycoplasmas in early pregnancy. J Clin Microbiol 2006, 44:51-55.

5. Patel MA, Nyirjesy P: Role of Mycoplasma and Ureaplasma species in female lower genital tract infections. Curr Infect Dis Rep 2010, 12:417-422.

6. Zdrodowska-Stefanow B, Kłosowska WM, Ostaszewska-Puchalska I, Bułhak-Kozioł V, Kotowicz B: Ureaplasma urealyticum and Mycoplasma hominis infection in women with urogenital diseases. Adv Med Sci 2006, 51:250-253

7. Kasprzykowska U, Elias J, Elias M, Maczyńska B, Sobieszczańska BM: Colonization of the lower urogenital tract with Ureaplasma parvum can cause asymptomatic infection of the upper reproductive system in women: a preliminary study. Arch Gynecol Obstet 2013. doi:10.1007/s00404-013-3102-7.

8. Rosemond A, Lanotte P, Watt S, Sauget AS, Gueriff F, Royere D, Goudeau A, Mereghetti L: Systematic screening tests for Chlamydia trachomatis, Mycoplasma hominis and Ureaplasma urealyticum in urogenital specimens of infertile couples. Pathol Biol 2006, 54:125-129.

9. Kasper DC, Mechtler TP, Reischer GH, Witt A, Langgartner M, Pollak A, Herkner KR, Berger A: The bacterial load of Ureaplasma parvum in amniotic fluid is correlated with an increased intrauterine inflammatory response. Diagn Microbiol Infect Dis 2010, 67:117-121.

10. Dhawan B, Malhotra N, Sreenivas V, Rawre J, Khanna N, Chaudhry R, Mittal S: Ureaplasma serovars and their antimicrobial susceptibility in patients of infertility and genital tract infections. Indian J Med Res 2012, 136:991-996.

11. De Francesco MA, Negrini R, Pinsi G, Peroni L: Detection of Ureaplasma biovars and polymerase chain reaction-based subtyping of Ureaplasma parvum in women with or without symptoms of genital infections. Eur J Clin Microbiol Infect Dis 2009, 28:641-646.

12. Paralanov V, Lu J, Duffy LB, Crabb DM, Shrivastava S, Methé BA, Inman J, Yooseph S, Xiao L, Cassell GH, Waites KB, Glass Jl: Comparative genome analysis of 19 Ureaplasma urealyticum and Ureaplasma parvum strains. BMC Microbiol 2012. doi:10.1186/1471-2180-12-88.

13. Waites KB, Katz B, Schelonka RL: Mycoplasmas and ureaplasmas as neonatal pathogens. Clin Microbiol Rev 2005, 18:757-789.

14. Kechagia N, Bersimis S, Chatzipanagiotou S: Incidence and antimicrobial susceptibilities of genital mycoplasmas in outpatient women with clinical vaginitis in Athens, Greece. J Antimicrob Chemother 2008, 62:122-125.

15. Bébéar CM, Bébéar C: Antimycoplasmal agents. In Molecular Biology and Pathogenicity of Mycoplasmas. Edited by Razin S, Herrmann R. London: Kluwer Academic/ Plenum Publishers; 2002:545-566.

16. Dongya $\mathrm{M}$, Wencheng $\mathrm{X}$, Xiaobo $\mathrm{M}$, Lu W: Transition mutations in $23 \mathrm{~S}$ rRNA account for acquired resistance to macrolides in Ureaplasma urealyticum. Microb Drug Resist 2008, 14:183-186. 
17. Xiao L, Crabb DM, Duffy LB, Paralanov V, Glass Jl, Hamilos DL, Waites KB: Mutations in ribosomal proteins and ribosomal RNA confer macrolide resistance in human Ureaplasma spp. Int J Antimicrob Agents 2011, 37:377-379.

18. Dégrange S, Renaudin H, Charron A, Bébéar C, Bébéar CM: Tetracycline Resistance in Ureaplasma spp. and Mycoplasma hominis: Prevalence in Bordeaux, France, from 1999 to 2002 and description of two tet(M)-positive isolates ofM. hominis susceptible to tetracyclines. Antimicrob Agents Chemother 2008, 52:742-744.

19. Mardassi BBA, Aissani N, Moalla I, Dhahri D, Dridi A, Mlik B: Evidence for the predominance of a single tet(M) gene sequence type in tetracycline-resistant Ureaplasma parvum and Mycoplasma hominis isolates from Tunisian patients. J Med Microbiol 2012, 61:1254-1261.

20. Raynes-Greenow CH, Roberts CL, Bell JC, Peat B, Gilbert GL, Parker S: Antibiotics for Ureaplasma in the vagina in pregnancy. Cochrane Database Syst Rev 2011, 9:CD003767. doi:10.1002/14651858.CD003767.pub3.

21. Santos F, Sheehy O, Perreault S, Ferreira E, Bérard A: Trends in anti-infective drugs use during pregnancy. J Popul Ther Clin Pharmacol 2012, 19:e.460-e.465.

22. Koh E, Kim S, Kim I, Maeng K, Lee S: Antimicrobial susceptibilities of Ureaplasma urealyticum and Mycoplasma hominis in pregnant women. Korean J Clin Microbiol 2009, 12:159-162.

23. Bébéar $\mathrm{CM}, \mathrm{Kempf} \mathrm{I}$ : Antimicrobial therapy and antimicrobial resistance. In Mycoplasmas: Molecular biology, Pathogenicity and strategies for control. Edited by Blanchard A, Browning GF. United Kingdom: Horizon Bioscience; 2005:535-568.

24. Miller JM, Martin DH: Treatment of Chlamydia trachomatis infections in pregnant women. Drugs 2000, 60:597-605.

25. Pitsouni E, lavazzo C, Athanasiou S, Falagas ME: Single-dose azithromycin versus erythromycin or amoxicillin for Chlamydia trachomatis infection during pregnancy: a meta-analysis of randomised controlled trials. Int J Antimicrob Agents 2007, 30:213-221.

26. Jacobson GF, Autry AM, Kirby RS, Liverman EM, Motley RU: A randomized controlled trial comparing amoxicillin and azithromycin for the treatment of Chlamydia trachomatis in pregnancy. Am J Obstet Gynecol 2001, 184:1352-1354.

27. Redelinghuys MJ, Ehlers MM, Dreyer AW, Lombaard HA, Kock MM: Comparison of the new Mycofast Revolution assay with a molecular assay for the detection of genital mycoplasmas from clinical specimens. BMC Infect Dis 2013, 13:453. doi:10.1186/1471-2334-13-453.

28. Sá Del Fiol F, Gerenutti M, Groppo FC: Antibiotics and pregnancy. Pharmazie 2005, 60:483-493.

29. Menard JP, Fenollar F, Henry M, Bretelle F, Raoult D: Molecular quantification of Gardnerella vaginalis and Atopobium vaginae loads to predict bacterial vaginosis. Clin Infect Dis 2008, 47:33-43.

30. CLSI: Methods for antimicrobial susceptibility testing for human mycoplasmas; Approved guideline. CLSI Document M43-A. Wayne, PA: Clinical and Laboratory Standards Institute; 2011

31. Domingues D, Tavira LT, Duarte A, Sanca A, Prieto E, Exposto F: Genital mycoplasmas in women attending a family planning clinic in Guiné-Bissau and their susceptibility to antimicrobial agents. Acta Trop 2003, 86:19-24.

32. Povlsen $K$, Thorsen $P$, Lind I: Relationship of Ureaplasma urealyticum biovars to the presence or absence of bacterial vaginosis in pregnant women and to the time of delivery. Eur J Clin Microbiol Infect Dis 2001, 20:65-67.

33. Govender S, Gqunta K, Le Roux M, De Villiers B, Chalkley L: Antibiotic susceptibilities and resistance genes of Ureaplasma parvum isolated in South Africa. J Antimicrob Chemother 2012, 67:2821-2824.

34. Zhu C, Liu J, Ling Y, Dong C, Wu T, Yu X, Hou Y, Dong L, Cheng X: Prevalence and antimicrobial susceptibility of Ureaplasma urealyticum and Mycoplasma hominis in Chinese women with genital infectious diseases. Indian J Dermatol Venereol Leprol 2012, 78:406-407.

35. Ardic N, Oncul O, Ilga U, Turhan V, Haznedaroglu T, Ozyurt M: Investigation of the frequency and antibiotic susceptibility of Mycoplasma/Ureaplasma in urine samples with leukocyturia by different commercial methods. Internet J Infect Dis 2005, 4. doi:10.5580/df

36. Roberts MC: Update on macrolide-lincosamide-streptogramin, ketolide, and oxazolidinone resistance genes. FEMS Microbiol Lett 2008, 282:147-159.

37. Romoren M, Velauthapillai M, Rahman M, Sundby J, Klouman E, Hjortdahl P: Trichomoniasis and bacterial vaginosis in pregnancy: inadequately managed with the syndromic approach. Bull World Health Organ 2007, 85:297-304.

38. White RG, Moodley P, McGrath N, Hosegood V, Zaba B, Herbst K, Newell M, Sturm WA, Hayes RJ: Low effectiveness of syndromic treatment services for curable sexually transmitted infections in rural South Africa. Sex Transm Infect 2008, 84:528-534.

39. Johnson LF, Dorrington RE, Bradshaw D, Coetzee DJ: The effect of syndromic management interventions on the prevalence of sexually transmitted infections in South Africa. Sex Reprod Healthc 2011, 2:13-20.

40. Lewis DA, Latif AS, Ndowa F: WHO global strategy for the prevention and control of sexually transmitted infections: time for action. Sex Transm Infect 2007, 83:508-509.

41. Cooper WO, Griffin MR, Arbogast P, Hickson GB, Gautam S, Ray WA: Very early exposure to erythromycin and infantile hypertrophic pyloric stenosis. Arch Pediatr Adolesc Med 2002, 156:647-650.

42. Farrar HC, Walsh-Sukys MC, Kyllonen K, Blumer JL: Cardiac toxicity associated with intravenous erythromycin lactobionate: two case reports and a review of the literature. Pediatr Infect Dis J 1993, 12:688-691.

43. Howe E, Howe E, Benn RA: Hepatotoxicity due to erythromycin ethylsuccinate. Med J Aust 1993, 158:142-144.

44. Lillis RA, Nsuami MJ, Myers L, Martin DH: Utility of urine, vaginal, cervical and rectal specimens for detection of Mycoplasma genitalium in women. J Clin Microbiol 2011, 49:1990-1992.

doi:10.1186/1471-2334-14-171

Cite this article as: Redelinghuys et al: Antimicrobial susceptibility patterns of Ureaplasma species and Mycoplasma hominis in pregnant women. BMC Infectious Diseases 2014 14:171.

\section{Submit your next manuscript to BioMed Central and take full advantage of:}

- Convenient online submission

- Thorough peer review

- No space constraints or color figure charges

- Immediate publication on acceptance

- Inclusion in PubMed, CAS, Scopus and Google Scholar

- Research which is freely available for redistribution 